\title{
URINARY CALCIUM AND KIDNEY STONES IN PARAPLEGIA. REPORT OF AN ATTEMPTED PROSPECTIVE STUDY
}

\author{
By R. G. Burr, A.R.I.C. and J. J. Walsh, M.D. \\ National Spinal Injuries Centre, Stoke Mandeville Hospital, \\ Aylesbury, Buckinghamshire
}

\section{INTRODUCTION}

AT the present time the main causal factor in the production of renal stones by paraplegic patients is considered to be infection of the urine by urea-splitting organisms, principally Proteus. This view is based on the chemical composition of the stones (Damanski, I963; Nordin, Hodgkinson, Peacock \& Robertson, 1969), clinical and bacteriological studies (McLeod, Mason \& Neill, I965) and the measurement of ion activity products in urine (Nordin et al., I969; Smith, Cook \& Robertson, 1969). Other factors may be involved and, in addition to antibiotic therapy and the use of urinary antiseptics, prophylactic measures include regular turning and the maintenance of a high fluid intake. In this situation the importance of the hypercalciuria during the first 6-I 8 months of paraplegia is uncertain.

It is possible that in some cases the elevated urinary calcium may initiate stone formation, via either a renal tubular lesion, or precipitation of calcium oxalate within the renal pelvis. Infection may then intervene to promote the growth of a stone consisting predominantly of magnesium ammonium phosphate. This would explain the paradox that an episode of hypercalciuria is followed, in susceptible individuals, by the formation of a mixed phosphate stone instead of the expected cxalate calculus.

A prospective study was begun to test this hypothesis, and also to attempt to identify those individuals most at risk from renal stone formation. Serial measurements of urinary calcium and other electrolytes were commenced in a group of paraplegic and tetraplegic patients, bacteriological examination of the urine was performed regularly, and the patients were followed up to see which of them would form stones.

No patient has yet produced a kidney stone. Nevertheless, the data are discussed here with reference to some of the biochemical changes that take place in paraplegic patients, and to their relevance to the study of stone disease.

\section{PATIENTS AND METHODS}

One hundred and sixty-nine patients, admitted to this Centre with spinal cord lesions between November I968 and April I97I, were studied. There were I 53 men and I6 women aged I5-68 (mean 3I.6) years. Two had paraplegia following infarction of the thoracic cord. The rest had traumatic lesions of the cord, complete in I03 (29 cervical, 57 thoracic, I 7 lumbar) and incomplete in 64 (3I cervical, 22 thoracic, I I lumbar). The levels of the cord lesions were assessed clinically. Management was by postural reduction (Guttmann, I963; Frankel et al., 1969) and intermittent catheterisation (Guttmann \& Frankel, I966). The 
fluid intake was such that the bladder contained about $20 \mathrm{oz}$. $(0.57 \mathrm{l}$.) urine each time it was emptied by catheter three times a day. When the patient began to pass urine spontaneously the fluid intake was increased to give about 5 pints (3 l.) urine daily. With this regimen, the patients began to pass urine spontaneously an average of 4.3 weeks after the onset of paraplegia, and catheterisation ceased at 8.8 weeks on average (Frankel, I97I).

Routine bacteriological examination of the urine was carried out every week while the patients were in hospital and at every out-patient attendance. Plain radiographs of the abdomen and intravenous pyelograms were obtained for the first time within 6 months of injury and at I- and 2-year intervals thereafter.

Biochemical Studies. Single 24-hour urine collections were obtained I, $2,3,4,6,8$, I2, I 6 and 20 weeks after injury where possible, although many patients were not admitted until several weeks after their accident, or were discharged before the end of the period of study. Owing to the difficulties of collecting complete 24-hour specimens, especially from female patients, the data for a large number of patients are unfortunately incomplete, and the results for only 83 male patients are presented here. For this group the mean age was 33.4 (range 17-68) years, and 49 patients had complete lesions (I 5 cervical, 28 thoracic, 6 lumbar) and 34 incomplete ( 8 cervical, I2 thoracic, 4 lumbar).

The urine specimens were strongly acidified with hydrochloric acid before analysis. At the commencement of the work, calcium was determined by the method of Clark and Collip, using a single wash of the calcium oxalate precipitate (Varley, 1967); magnesium by Schachter's (196I) method modified by prior precipitation of calcium using one-third saturated ammonium oxalate adjusted to $\mathrm{pH} 4.5$ with acetic acid; inorganic phosphate by a modification of the method of Fiske and Subbarow (King \& Wootton, I956); creatinine by Bonsness and Taussky's method (Varley, I967); and sodium and potassium by flame photometry. In December 1969 improved facilities were made available, and since then calcium and magnesium have been measured by atomic absorption spectrophotometry and inorganic phosphate and creatinine by the AutoAnalyser (Technicon Instruments Co. Ltd., Baskingstoke).

\section{RESULTS}

Follow-up. To date (March I973) 29 of the I69 patients have made good recoveries and regained sphincter control. Eight patients have died, post-mortem examination results being available in seven. For 84 others the results of intravenous pyelography are available 12 months or more after the onset of paralysis, and for 42 of these I.V.P. results are available at least 2 years after injury. In the group as a whole, 60 patients have had at least one episode of infection by an organism of the Proteus group, and in 12 this has been persistent.

No calculi have been detected in the upper urinary tract of any patient, but four have developed bladder stones and one a urethral calculus. One of these was a woman who was found to have a stone in her bladder only 2 months after becoming paraplegic, but had a history of repeated urinary tract infection before injury. In three others the calculi were associated with Proteus infection and an indwelling urethral catheter. In the remaining patient, removal of the stone was preceded by two episodes of infection by Klebsiella aerogenes and one by Aerobacter cloacae, and followed by an episode of Proteus mirabilis infection. 
Biochemical Measurements. The results of the biochemical analyses for 83 of the male patients are shown in Figure $\mathrm{I} .{ }^{1}$ Urine specimens obtained from a further 50 of the patients for 5 consecutive days during the 7 th week of paraplegia gave results close to those shown in Figure .I for week $6 .^{1}$
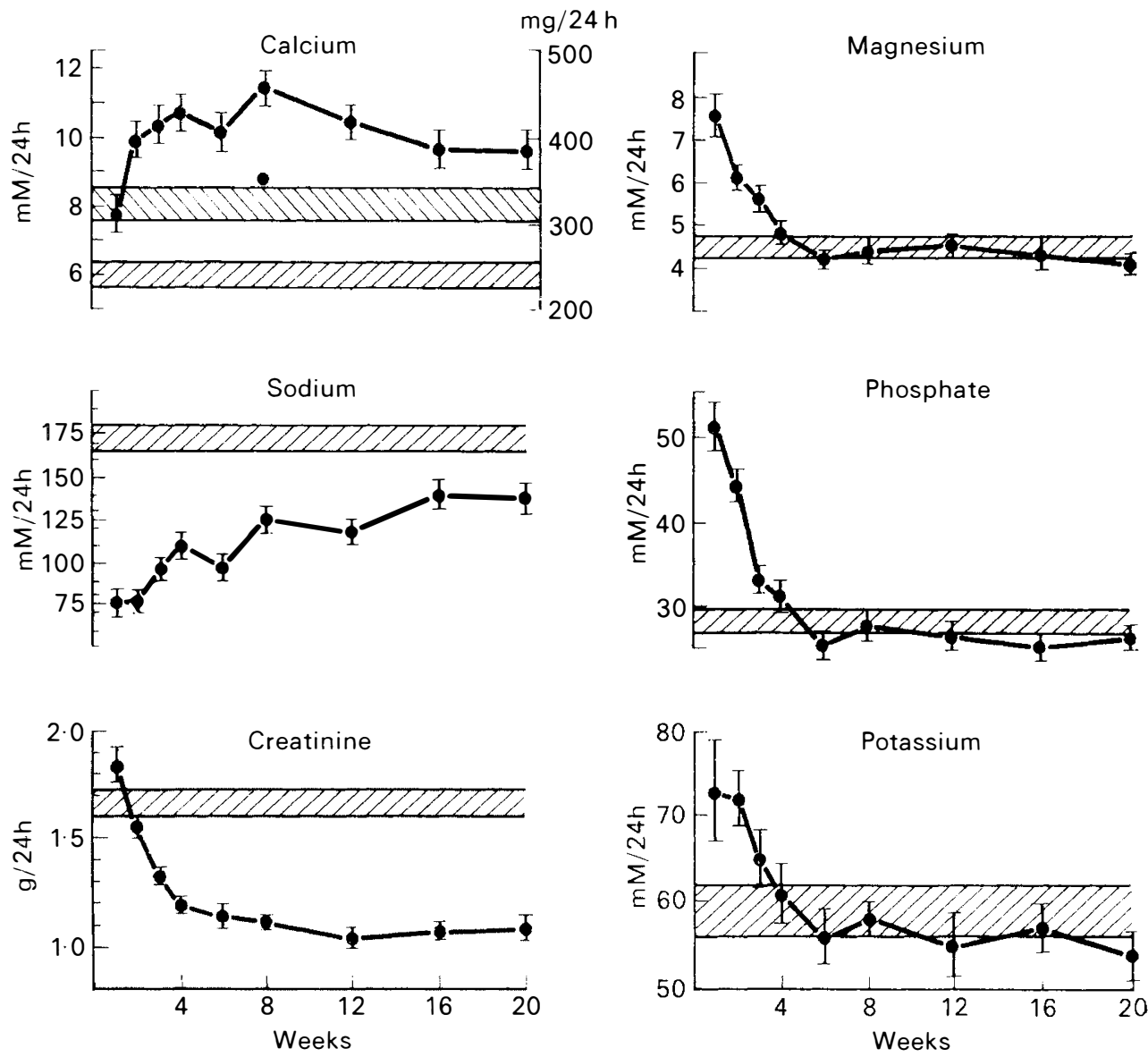

Z Healthy subjects $\Phi$ Calcium stone patients

FIG. I

Urinary excretion of electrolytes and creatinine in a group of 83 male patients with spinal cord injury. The values for control subjects and calcium-stone patients are those of Robertson, Peacock \& Nordin (1968). Means \pm Standard error are shown.

The mean urinary calcium was elevated throughout the period of observation. In individual patients there was often a peak in calcium excretion between weeks 4 and 8. Different patients with the same level of cord lesion exhibited widely differing calcium excretion, and there was no correlation between calcium output and the degree of paralysis. This was so in spite of the fact that six of the patients studied were only slightly paralysed and made complete recoveries. In addition,

\footnotetext{
${ }^{1}$ Complete data available on request.
} 
three non-paraplegic patients who were managed by postural reduction in an identical manner to the paraplegics (that is, with immobilisation of the spine but with regular limb movements for 8 to I 4 weeks after injury) also had very high urinary calcium, the mean values after week 4 being 390,426 and $626 \mathrm{mg}$. $/ 24$ hours. ${ }^{1}$ Elderly patients excreted less calcium than those under the age of 60 , but there were only four over 60 years of age and the relationship was not significant.

The pattern of excretion of the other urinary electrolytes measured was very variable but in general it can be said that after an initial increase the urinary magnesium, phosphate and potassium fell to, and remained close to, the normal range, and that the urinary sodium was subnormal throughout and in only a few patients did the excretion rise to the normal range. Some patients, however, had a very high sodium output in the first few weeks. The urinary excretion of creatinine fell rapidly in almost all patients and remained well below the range reported in healthy subjects (fig. I).

\section{DISCUSSION}

Since no kidney stones have occurred, no conclusions can be drawn about their aetiology, and the objective of the early recognition of the at-risk patient remains unfulfilled. The reasons for this lack of success are discussed below, followed by some comments on the metabolic changes that result from spinal cord injury.

Stone Disease. The mean urinary calcium excretion of the patients studied was much greater than that observed in hypercalciuric renal stone patients (fig. I). In spite of this there was no evidence that a stone had occurred in any patient. This indicates that the fluid intake was sufficient to enable the kidneys to handle the excreted load of calcium, and also that antibiotic therapy was effective in preventing the growth of stones of infection. (It should be noted that the regimen adopted will be expected to prevent the excretion of a highly concentrated urine at any time of day or night.)

Alternatively, there may have been insufficient time for stones to develop. In Comarr's (1955) series 50 per cent. of renal stones occurred in the first year and 70 per cent. in the first 18 months, indicating that at that time the greatest risk of stone formation was during the first 2 years following the onset of paraplegia. Guttmann and Frankel (I966), however, in an I I-year follow-up study of 344 paraplegics, of whom eight formed stones, found only one stone during the first year and five ( 62 per cent.) during the second and third years. The value of the present series will increase if the patients can be followed for a much longer period.

A wide variety of organisms was encountered in the urines from these patients, but no attempt was made to determine the site of infection. A constant association between the presence of organisms of the Proteus group and stone disease in paraplegic patients was noted by Damanski (1963) and by McLeod et al. (1965). In four of the present patients infection by Proteus, together with the nucleating effect of an indwelling catheter, were probably responsible for the production of bladder stones.

Biochemical Findings. The urinary calcium output was not related to the level of the spinal cord lesion, whether complete or incomplete. A similar

\footnotetext{
${ }^{1}$ Complete data available on request.
} 
observation was made by Dunning and Plum (1957) in their study of poliomyelitis patients. The high urinary calcium of the three patients with spinal fracture who were not paralysed is of considerable interest. Bedfast healthy subjects show an increased urinary calcium which reaches a maximum (of $305.7 \pm 49 \cdot 0 \mathrm{mg}$./ day (mean \pm S.E.M.)-calculated from the data of Deitrick, Whedon \& Shorr, I948, and of Donaldson et al., 1970) in about 6 weeks and declines slowly thereafter. The more severe hypercalciuria of the injured patients in the present study may have been due to their greater restriction of movement (complete immobility of the spine), or it may have been an effect of trauma. The number of subjects studied was, however, very small.

Skeletal demineralisation in immobilised subjects has been thought to be due to the removal of weightbearing stresses on long bones. The evidence is both clinical and experimental (Abramson, I948; Solomons, Shuster \& Kwan, I965; Jenkins \& Cochran, I969). A possible mechanism involves piezoelectric effects in bone (Shamos, Lavine \& Shamos, I963; Bassett, Pawluk \& Becher, I964). Recent evidence, however, indicates that calcium excretion in paraplegia is related to changes in volume of the extracellular fluid (Griffith, I97I; Claus-Walker et al., I972).

The variability of urinary calcium from patient to patient, which was considerable, may have been related to differences in extracellular volume, in bone metabolism, or in intestinal absorption. Calcium absorption is reduced in immobilised subjects, and there is an associated increase in faecal excretion (Heaney, I960; Rose, I966). Differences in urinary calcium may be due to differences in the efficiency with which calcium absorption is suppressed.

The low mean output of sodium observed in our patients was probably related to low dietary intake, the initially elevated urinary potassium, magnesium and phosphate were consistent with the known metabolic response to trauma, and the falling creatinine excretion was probably a consequence of the decline in muscle mass which follows paralysis.

\section{SUMMARY}

Serial biochemical, radiological and bacteriological investigations were carried out in 169 patients following damage to the spinal cord. Follow up was from 2 to 4 years. Results of intravenous pyelography are available 12 months or more after the onset of paralysis in 84 patients, and at least 24 months after paralysis in 42. No stones have been found in the upper urinary tract of any patient, but there were five cases of calculosis of the lower urinary tract. The period of follow-up must be greatly extended before definite conclusions can be drawn. Three additional patients with spinal fracture without neurological impairment showed hypercalciuria of comparable severity to that of the paraplegics, but greater than that reported by other workers for bedfast healthy subjects.

Acknowledgements. The bacteriological and radiological examinations were carried out in the appropriate Hospital Departments under Drs. C. L. Greenbury and R. Spalding Smith respectively. We also thank Dr. A. Barr for the statistical analyses; Wing-Cdr. A. Broughton and the staff of the R.A.F. Institute of Pathology and Tropical Medicine, Halton, Aylesbury for the calcium, magnesium, creatinine and phosphate determinations; and Mrs. I. Kardos for technical assistance. 


\section{REFERENCES}

Abramson, A. S. (1948). F. Bone Foint Surg. 30A, 982.

Bassett, C. A. L., Pawluk, R. J. \& Becher, R. O. (I964). Nature, 204, 652.

Claus-Walker, J., Campos, R. J., Carter, R. E., Vallbona, C. \& Lipscomb, H. S. (I972). Arch. phys. Med. Rehabil. 53, I4.

Comarr; A. E. (1955). F. Urol. 74, 447.

DAMANSKI, M. (I963). Paraplegia, I, I 49 .

Deitrick, J. E., Whedon, G. D. \& Shorr, E. (1948). Amer. F. Med. 4, 3.

Donaldson, C. L., Hulley, S. B., Vogel, J. M., HattNer, R. S., Bayers, J. H. \& McMillan, D. E. (1970). Metabolism, 19, I07I.

Dunning, M. F. \& Plum, F. (1957). Arch. int. Med. 99, 7 I6.

FRANKEL, H. L. (I97I). Proceedings of the I8th Veterans Administration Spinal Cord Injury Conference, p. 132.

Frankel, H. L., Hancock, D. O., Hyslop, G., Melzak, J., Michaelis, L. S., Ungar, G. H., Vernon, J. D. S. \& Walsh, J. J. (1969). Paraplegia, 7, I79.

Griffith, D. P. (I97I). F. Urol. I05, 698.

Guttman, L. (1963). Paraplegia, I I 76.

Guttmann, L. \& Frankel, H. L. (I966). Paraplegia, 4, 63

HeANey, R. P. (1960). F. Lab. clin. Med. 56, 825.

Jenkins, D. P. \& Cochran, T. H. (1969). Clin. Orthop. 64, I 28

KIng, E. J. \& Wootton, I. D. P. (1956). Microanalysis in Medical Biochemistry, London: Churchill.

Mcleod, J. W., Mason, J. M. \& Neill, R. W. K. (1965). Paraplegia, 3, I24.

Nordin, B. E. C., Hodgrinson, A., PeAcock, M. \& Robertson, W. G. (I969). Fifth Symposium on Advanced Medicine, ed. R. Williams, p. 236. London: Pitman Medical.

Robertson, W. G., Peacock, M. \& Nordin, B. E. C. (1968). Clin. Sci., 34, 579.

Rose, G. A. (I966). Br. F. Surg. 53, 769.

SCHACHTER, D. (I96I). F. Lab. clin. Med. 58, 495.

Shamos, M. S., Lavine, L. S. \& Shamos, M. I. (1963). Nature, 197, 81.

SMith, P. H., Cook, J. B. \& Robertson, W. G. (1969). Paraplegia, 7, 77.

Solomons, C. C., Shuster, D. \& Kwan, A. (1965). Aerospace Med. 36, 33.

VARLey, H. (1967). Practical Clinical Biochemistry, London: Heinemann. 